\title{
Photo Medicine and Laser Surgery in Pedodontics: A Case Series
}

\author{
Alex Mathews Muruppe ${ }^{1 *}$, Sheen Ann John ${ }^{2}$, Anoop Harris ${ }^{2}$, Gayathri Krishnan ${ }^{2}$ and RobinTheruvil ${ }^{3}$ \\ ${ }^{1}$ Department of Surgical Sciences and Integrated Diagnostics, University of Genova, Genova, Italy \\ ${ }^{2}$ Department of Pedodontics and Preventive Dentistry, P.M.S College of Dental Science and Research, \\ Thiruvananthapuram, Kerala, India \\ ${ }^{3}$ Department of Conservative Dentistry \& Endodontics, St. Gregorios Dental College, Kothamangalam, \\ Kerala, India
}

\section{Introduction}

Laser applications in paediatric dentistry can be thought of as an alternative treatment that sometimes completes or otherwise substitutes traditional techniques. Various clinical modalities could be performed on both hard and soft tissues using lasers of various wavelengths. Among the plethora of advantages that lasers can provide in paediatric dentistry, minimally invasive and painless treatments using lasers are comforting, particularly from the perspective of a young patient as they avoid the need for painful injections or the vibration and heat generated by drills. Diode lasers ( $810 \mathrm{~nm}-980$ $\mathrm{nm}$ ) used in soft tissue procedures and the Erbium family of lasers (Er.Cr.YSGG 2780 nm \& Er.YAG 2940 nm) which could be employed for both hard and soft tissues, are both able to provide analgesic effect by numbing nerve fibres through several postulated mechanisms [1]. Furthermore, Erbium lasers allow selective removal of carious enamel and dentin with a precision of 4-20 $\mu$, thus precluding the unwarranted destruction of sound tooth structure, a feature which holds distinct benefit when we consider the thinner enamel and dentin of the deciduous dentition. All these features coupled with Low Level Laser Therapy (LLLT) which stimulates and speeds up the body's own healing and reparative mechanisms make laser dentistry and invaluable tool as a treatment modality in paediatric dentistry.

This article illustrates the use of lasers in soft tissue and hard tissue and in different clinical scenarios through a series of case reports.

\section{Case Series Reports}

\section{Case report 1}

Pyogenic granuloma: A 12-year-old male patient reported with a red smooth surfaced mass, which was variably compressible and would bleed readily [2] and was engulfing the lower left first premolar. An $810 \mathrm{~nm}$ Diode (GaAlAs) Laser was used at 0.8 W, Continuous Wave (C.W.) with $320 \mu$ initiated fiber tip under topical application of Precaine ${ }^{\circledR}(8 \%$ Lidocaine,
0.8\% Bupivacaine) for 3 minutes (Total Energy $144 \mathrm{~J}$ ). Biostimulation was provided in conjunction with a flat end (Photobiomodulation) handpiece ( $0.3 \mathrm{~W}$, Total Energy $3 \mathrm{~J}$, Energy density with movement $(5 \mathrm{~mm} / \mathrm{sec}) 0.2 \mathrm{~J} / \mathrm{cm}^{2}, 10$ secs exposure time), every alternate day for 1 week. Healing was assessed after two weeks. The healing was uneventful, and analgesics prescribed were not taken, and no discomfort or swelling was reported (Figure 1, Figure 2, Figure 3 and Figure 4).

\section{Case report 2}

Lingual frenectomy: An 8-year-old boy presented with

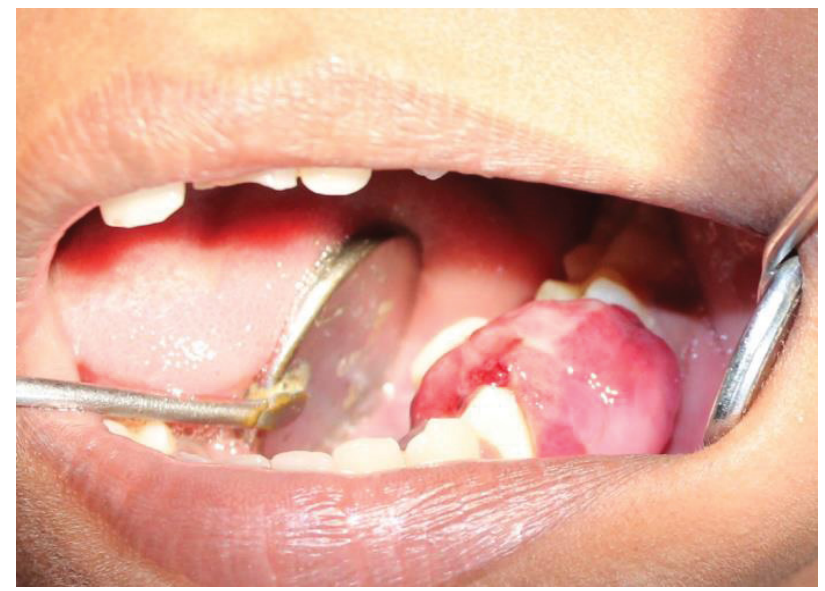

Figure 1: Pre-operative view of pyogenic granuloma.

*Corresponding author: Alex Mathews Muruppel, Department of Surgical Sciences and Integrated Diagnostics, University of Genova, 16132 Genoa (GE), Genova, Italy

Accepted: November 28, 2020

Published online: November 30, 2020

Citation: Muruppel AM, John SA, Harris A, et al. (2020) Photo Medicine and Laser Surgery in Pedodontics: A Case Series. Archives Oral Maxillofac Surg 3(1):77-81 


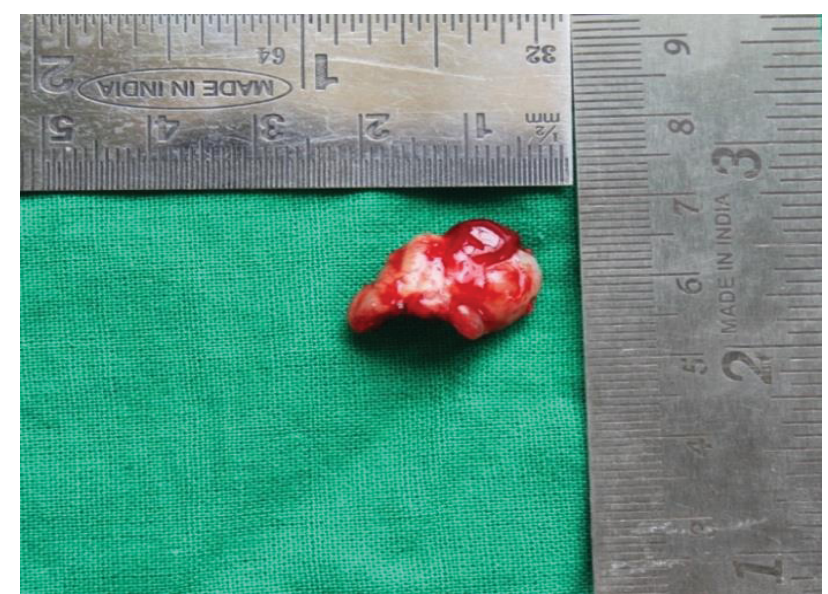

Figure 2: Excised pyogenic granuloma.

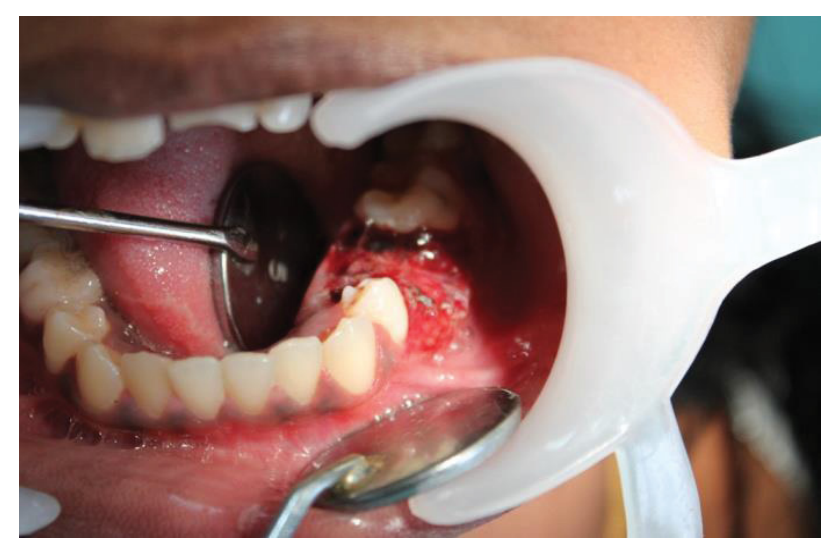

Figure 3: Immediate post-operative view after excision.

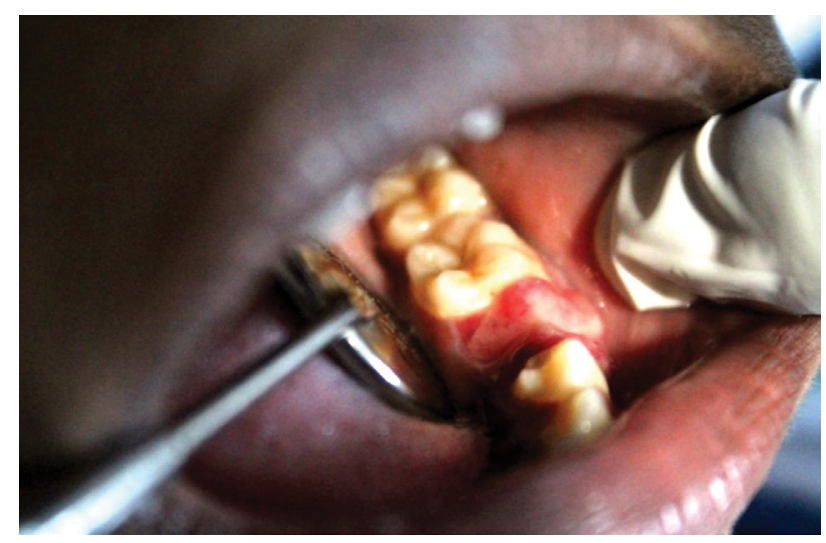

Figure 4: Post-operative view after 2 weeks.

difficulty in speech, examination revealed reduced mobility of the tongue due to short lingual frenum. The tongue tie was a Class II according to Kotlow [3,4] with $75 \%$ restriction of movement. Hence a frenectomy was performed using a $810 \mathrm{~nm}$ Diode (GaAlAs) Laser at $1.2 \mathrm{~W}$, Gated Pulsed Mode at $50 \%$ duty cycle with a $320 \mu$ initiated fiber tip under topical application of Precaine ${ }^{\circledR}$ for 2.5 minutes (Total Energy 90 J).The healing was uneventful and analgesics prescribed were not taken. Complete freedom of tongue movement with a

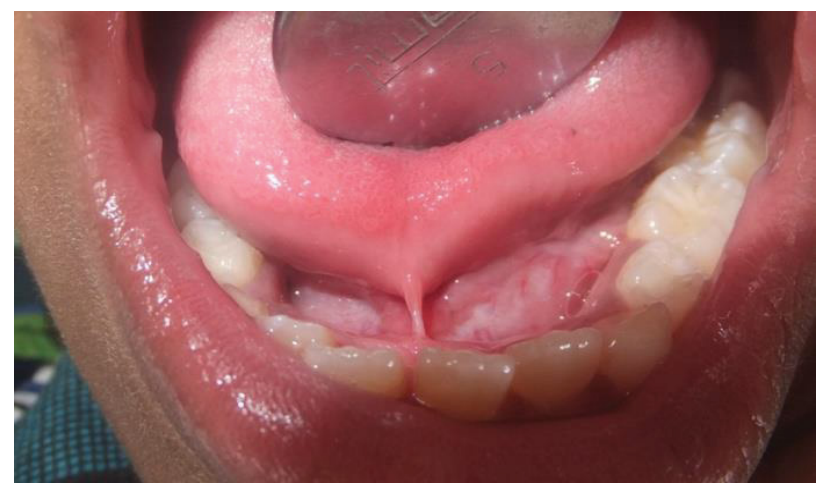

Figure 5: Pre-operative view before lingual frenectomy.

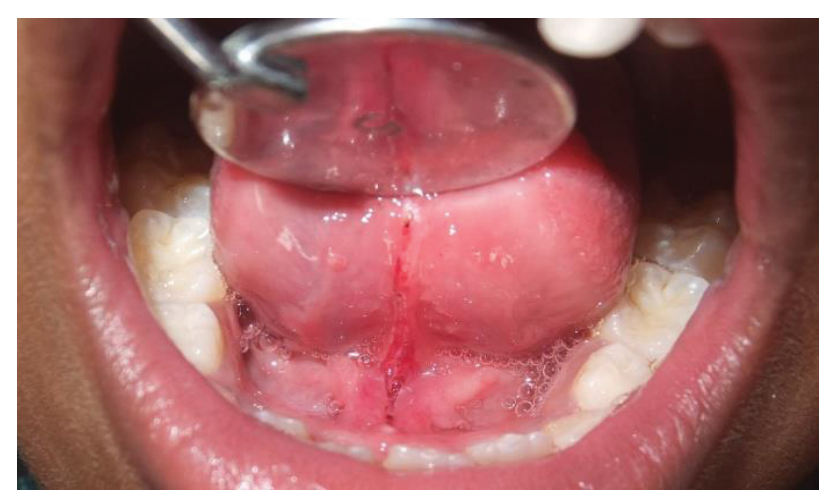

Figure 6: Immediate post-operative view after excision.

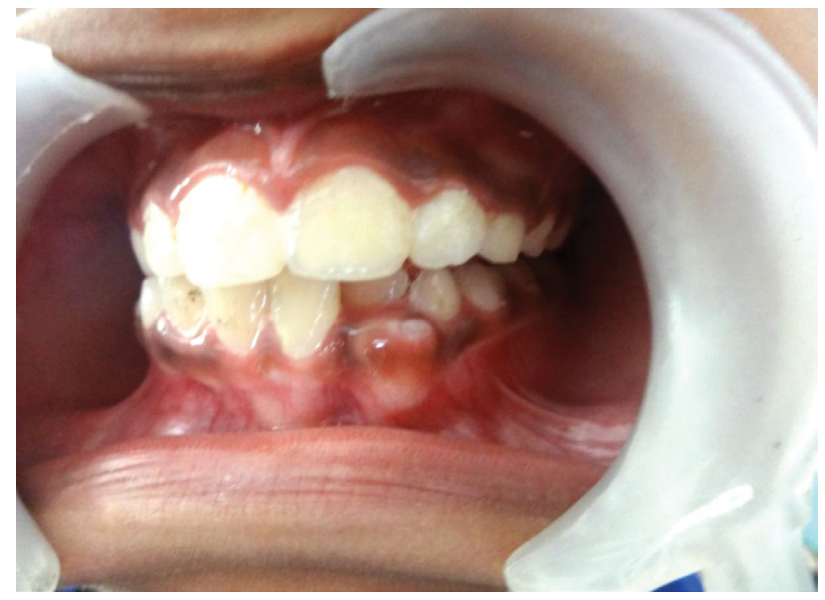

Figure 7: Post-operative view after 2 weeks.

marked improvement in speech clarity and pronunciation of syllables was noted 2 weeks after healing (Figure 5, Figure 6 and Figure 7).

\section{Case report 3}

Mucosal exposure: An 8-year-old girl on routine checkup was found to have a supernumerary tooth anterior to a lingually placed left lateral incisor. Extraction of this supernumerary tooth was found to be difficult due to the mucosal coverage. Hence a mucosal exposure was planned with $810 \mathrm{~nm}$ Diode (GaAlAs) Laser at $0.8-1 \mathrm{~W}$, Continuous Wave 


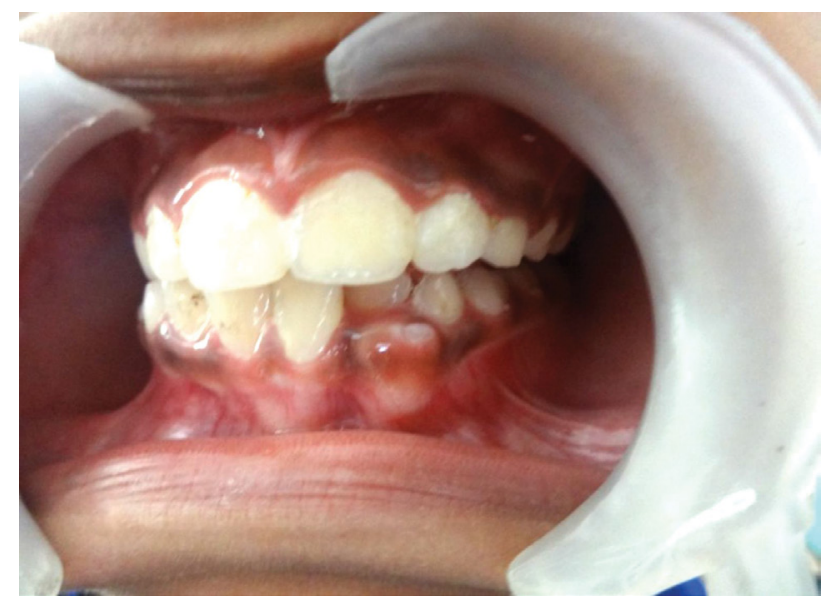

Figure 8: Pre-operative view of supernumerary tooth with mucosal coverage.

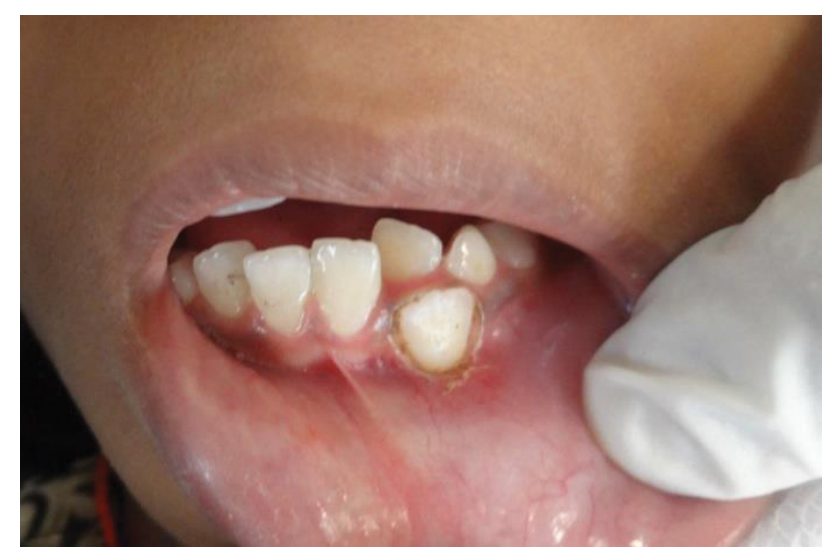

Figure 9: Immediate post-operative view after mucosal exposure using laser.

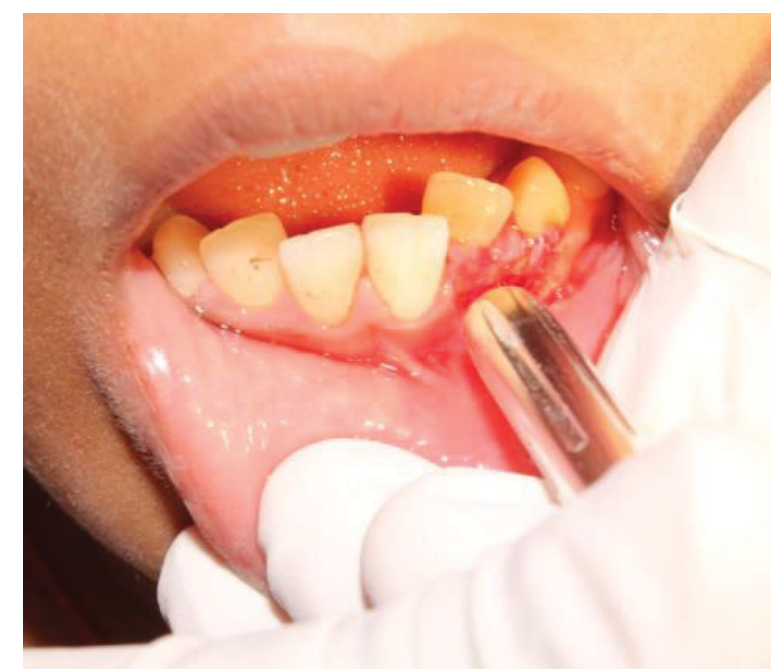

Figure 10: Biostimulation after removal of the supernumerary tooth.

(C.W.) with $320 \mu$ initiated fiber tip under topical application of Precaine ${ }^{\circledR}$ for a total time of 3.5 minutes (Total Energy approx.162 J). Local anesthesia was administered only during

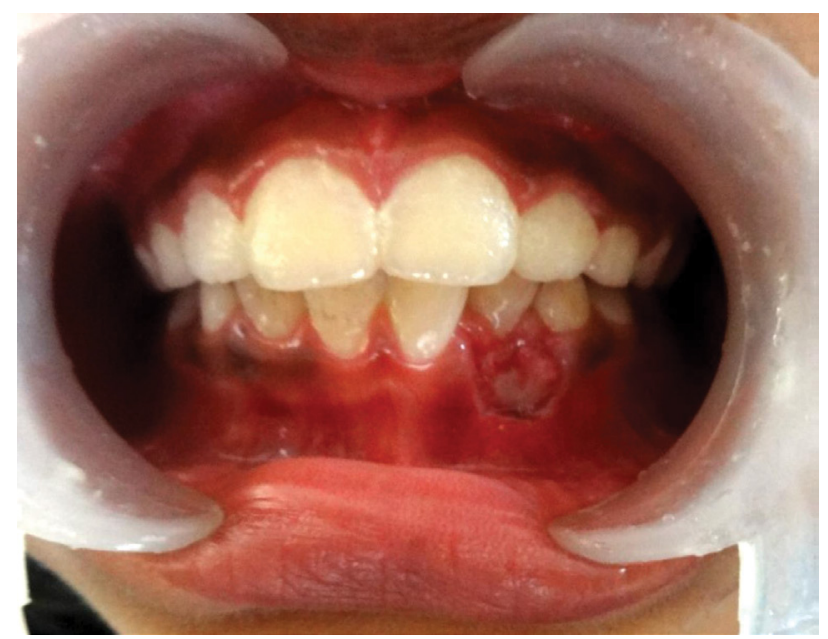

Figure 11: Post-operative healing after 10 days.

extraction of the supernumerary tooth on the same day. Biostimulation was administered in the same regimen as in Case 1. A 10-day post-operative review showed excellent healing with no post-operative discomfort (Figure 8, Figure 9, Figure 10 and Figure 11).

\section{Case report 4}

Laser assisted root canal treatment: An 11-year-old male patient reported with severe pain particularly at night in the lower left back tooth region. On examination, deep dentinal caries was noticed in relation to 36 with tenderness to percussion. Radiographs revealed radiolucency involving the pulp and also widening of periodontal ligament. The root canal was accessed using the erbium laser (Er.YAG $2940 \mathrm{~nm}$ ) [5] after achieving analgesia using the Olivi-Genovese technique [1] by positioning the $800 \mu$ sapphire tip around $10 \mathrm{~mm}$ away from the tooth at a very low energy and frequency (25-50 mJ, $10-15 \mathrm{~Hz}$ ) for nearly a minute and then gradually increasing the energy and frequency on observing the patient being able to tolerate the laser energy, and thereafter bringing it to focus on the carious area and ablate the tooth structure.

The root canals were treated using the Genovese protocol, which consisted of first applying the Diode Laser 810nm at $1 \mathrm{~W}$ continuous wave (C.W.), dwelling not more than 10 secs per root canal, going to the working length but activating the laser only after pulling out $1 \mathrm{~mm}$ in a saline irrigated canal (to remove the smear layer and disinfection) and thereafter irrigating the root canal with $10 \%$ citric acid solution and activating the laser $(1 \mathrm{~W}, \mathrm{C} . \mathrm{W}$.$) in the root canal in a pumping$ fashion (Laser activated irrigation) (Figure 12, Figure 13 and Figure 14).

\section{Discussion}

Laser applications in both hard and soft tissues have become quite popular in paediatric dentistry recently. Lasers present several advantages over conventional methods in hard tissue preparation such as minimal vibration, pressure, noise and pain [6]. Similarly, compared to scalpel surgery, lasers reduce or eliminate bleeding intra-operatively, which improves visibility of the site and reduces operating time [6] 


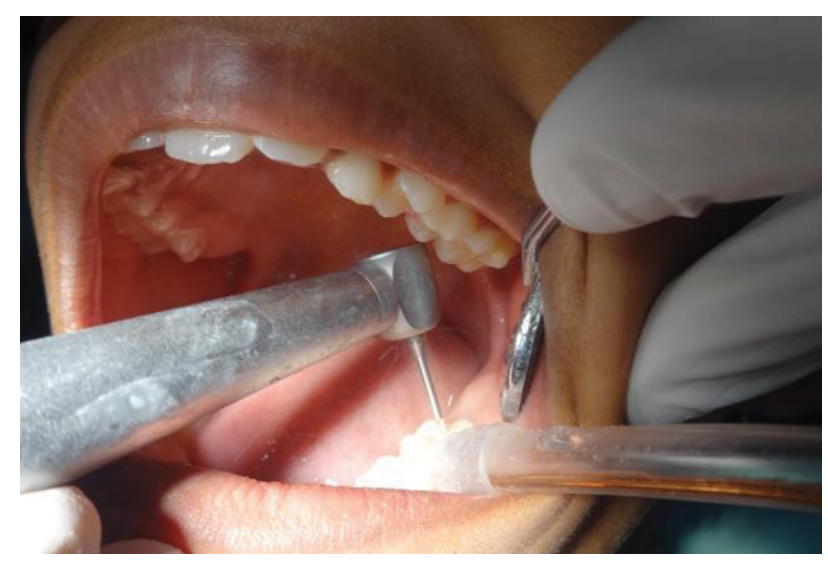

Figure 12: Laser assisted access opening of tooth no: 36.

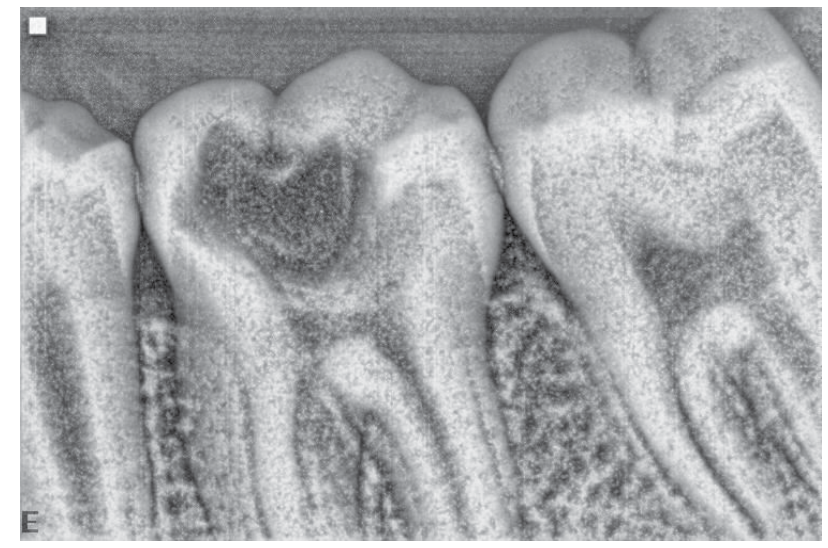

Figure 13: Preoperative radiograph of tooth no: 36.

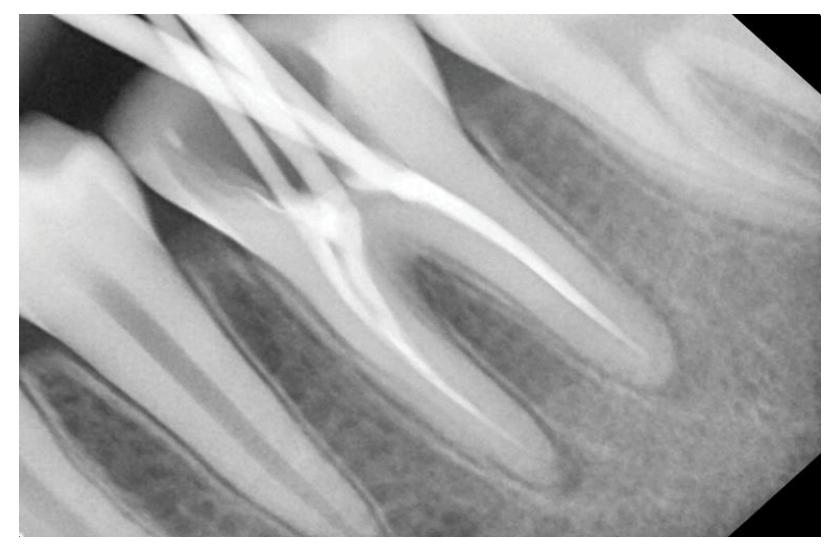

Figure 14: Post Operative radiograph of tooth no: 36.

and even postoperatively which speeds up the healing process. The laser seals blood vessels and reduces bacteraemia $[7,8]$. The coagulated surface layer created by lasing serves as a scaffold for healing and acts as a wound dressing. Thus, the laser eliminates the need to suture and creates an infection free site [9]. No sutures were placed in any of the above soft tissue cases and the healing assessed on the subsequent visit was promising. The laser seems to obviate the need for antibiotics too. These findings were consistently observed in all of the above case reports.
Notably, the preclusion or minimal use of local anesthesia reduces the levels of stress and anxiety in patients. An antalgic effect can be achieved through "laser analgesia" where lower energies and higher pulse frequencies can numb the tooth without effecting surface ablation of the tooth structure [10]. Significantly all the cases illustrated were performed only under topical anaesthesia.

Bio stimulation or low-level laser therapy (LLLT) is another effective laser application. This occurs through the photochemical effect caused by the action of visible red (633-635 $\mathrm{nm})$ or near infra-red (810-830 $\mathrm{nm}$ ) laser light which energizes the electron transport chain within the mitochondria, activates Cytochrome $\mathrm{C}$ oxidase (and other enzymes) in the inner mitochondrial membrane, and causes a broad activation of normal cellular functions [10]. Many studies have shown evidence that LLLT is particularly beneficial when used after a surgical procedure. Wounds treated thus do not experience post- operative hemorrhage and show little or no post-operative pain.

Surgical procedures are often associated with a lot of pain, bleeding, and infection and in turn related to a lot of stress and anxiety in the paediatric patient. The introduction of lasers endows the patient a stress-free procedure and reduces post-operative discomfort.

\section{Conclusion}

Lasers can definitely be considered as an alternative or adjunct to the conventional methods, provided a thorough knowledge of the type of laser to be used, frequency and amount of time to be applied is mastered. Due emphasis should also be given for laser safety procedures for the patient as well as the operator.

\section{Disclaimer}

The authors wish to state that this article is not constrained or influenced by any financial, or commercial interests and has not received any grants nor been influenced by any company or commercial institution.

\section{References}

1. Olivi G, Olivi M (2015) Laser in restorative dentistry. In: Laser application for restorative dentistry. Springer International Publishing, 144-145.

2. Savage NW, Daly CG (2010) Gingival enlargements and localized gingival overgrowths. Aust Dent J 55: S55-S60.

3. Kotlow LA (1999) Ankyloglossia (tongue tie): A diagnostic and treatment quandary. Quintessence Int 30: 259-262.

4. Olivi G, Margolis FS, Genovese MD (2011) Pediatric laser dentistry. In: Soft tissue Laser Applications. ( $1^{\text {st }}$ edn), Quintessence Publishing Co, China, 121-157.

5. Schoop U, Moritz A, Kluger W, et al. (2002) The Er: YAG laser in Endodontics: Results of an in vitro study. Lasers Surg Med 30: 360-364.

6. Guler C, Malkoc MA, Gorgen VA, et al. (2014) M. Effects of Er:YAG Laser on mineral content of sound dentin in primary teeth. Scientific World Journal. 
Citation: Muruppel AM, John SA, Harris A, et al. (2020) Photo Medicine and Laser Surgery in Pedodontics: A Case Series. Archives Oral Maxillofac Surg 3(1):77-81

7. Walsh JL (2010) Maximising gingival aesthetics using lasers. Australian dental Practise July/August 52-56.

8. Kimura Y, Wilder-Smith P, Matsumoto K (2000) Lasers in endodontics: A review. Int Endod J 33: 173-185.
9. Swick DM, Richter A (2003) A comparative study of two intraoral laser techniques for soft tissue surgery.

10. Walsh JL (2006) Laser dentistry: Membrane-based photoacoustic and bio stimulatory applications in clinical practice. Australasian Dental Practice 17: 62-64. 